\title{
Numerical Analysis Effect of Home Roof Design Towards Thermal Comfort of Occupants
}

\section{Analisis Numerik Pengaruh Desain Atap Rumah Terhadap Kenyamanan Termal Penghuni}

\author{
Denda Afri Juliadi' ${ }^{1}$, Remon Lapisa ${ }^{1}$, Purwantono ${ }^{1}$, Hendri Nurdin ${ }^{1}$
}

\begin{abstract}
The cool room temperature is a requirement in the thermal comfort of a building. In earthquake prone areas, building structures should be designed with minimal material weight. Therefore, it is necessary to be aware of an alternative solution to ensure the room's thermal comfort with minimal weight. This research aims to analyze the influence of roof slope $15^{\circ}, 20^{\circ}, 25^{\circ}, 30^{\circ}, 35^{\circ}, 40^{\circ}$, and $45^{\circ}$ on the comfort of the room and the strength of the building in the house measuring 6 meters $x 8$ meters $x 3$ meters. Analysis is done with three software that is SketchUp as a design, CONTAM to analyze air pressure and TRNSYS to simulate all the data that has been created in SketchUp and CONTAM. Obtained the lowest temperature at a roof slope of $45^{\circ}$ and the lowest weight is the roof with a $15^{\circ}$ slope.
\end{abstract}

\section{Keywords}

tilt roof, room temperature, simulation, thermal comfort

\begin{abstract}
Abstrak
Temperatur ruangan yang sejuk merupakan syarat dalam kenyamanan termal sebuah bangunan. Di kawasan rawan gempa, struktur bangunan harus dirancang dengan bobot material yang minimal. Oleh karena itu, perlu dicarikan solusi alternatif untuk menjamin kenyaman termal ruangan dengan bobot yang minimal. Penelitian ini bertujuan menganalisis pengaruh kemiringan atap $15^{\circ}, 20^{\circ}, 25^{\circ}, 30^{\circ}, 35^{\circ}$, $40^{\circ}$, dan $45^{\circ}$ terhadap kenyamanan ruangan serta kekuatan bangunan pada rumah berukuran 6 meter x 8 meter x 3 meter. Analisis dilakukan dengan tiga software yaitu SketchUp sebagai perancangan, CONTAM untuk menganalisis tekanan udara serta TRNSYS untuk menyimulasikan semua data yang telah di buat pada SketchUp dan CONTAM. Didapatkan hasil suhu terendah berada pada kemiringan atap $45^{\circ}$ dan bobot terendah adalah atap dengan kemiringan $15^{\circ}$.
\end{abstract}

Kata Kunci

Kemiringan atap, Temperatur Ruangan, Simulasi, Kenyamanan Termal.

${ }^{1}$ Pendidikan Teknik Mesin, Universitas Negeri Padang

Jl. Prof. Dr. Hamka, Kel. Air Tawar, Padang, Sumatera Barat. Kode Pos: 25132

*afrydj24.ad@gmail.com

Submitted : February 05, 2020. Accepted : February 17, 2020.Published : May 01, 2020.

This is an open access article distributed under the Creative Commons 4.0 Attribution License 


\section{PENDAHULUAN}

Indonesia merupakan negara beriklim tropis dengan suhu dan kelembaban udara yang tinggi. Suhu dan kelembaban yang tinggi membuat manusia menjadi tidak nyaman. Kenyamanan termal dibutuhkan manusia agar merasa nyaman saat berada di suatu ruangan, batas kenyamanan untuk kondisi khatulistiwa adalah pada kisaran suhu udara $22,5^{\circ} \mathrm{C}-29^{\circ} \mathrm{C}$ dengan kelembapan udara antara 20\% - 50\% [1]. Kondisi termal yang nyaman dapat membantu tubuh manusia mempertahankan suhu badan idealnya yang berkisar $37^{\circ} \mathrm{C}$. Suhu badan ideal dibutuhkan agar organ tubuh dapat berfungsi dengan baik [2].

Atap merupakan salah satu komponen utama dari sebuah bangunan. Saat ini terdapat berbagai macam desain atap yang dapat digunakan pada bangunan. Setiap negara memiliki desain atap yang berbeda tergantung iklim dan letak geografis negara tersebut. Desain atap yang berbeda tentunya memiliki fungsi yang berbeda pula. Atap bangunan mempunyai peran yang sangat penting baik secara fungsional maupun secara estetis. Secara fungsional atap merupakan bagian yang paling besar perannya dalam memberikan perlindungan terhadap iklim karena merupakan bagian yang paling sering terpapar panas dan hujan. Sedangkan secara estetis, atap merupakan elemen yang sangat menentukan ciri atau karakter suatu bangunan.

Pemilihan desain atap yang kurang tepat untuk suatu bangunan dapat menyebabkan ketidaknyamanan penghuni di dalamnya. Untuk menciptakan kenyamanan ruangan, bangunan sering dilengkapi dengan Pendingin Ruangan sehingga meningkatkan konsumsi energi listrik. Konsumsi energi listrik dalam rumah hunian di daerah tropis mencapai 40\% dari total konsumsi nasional [3]. Sedangkan untuk mendinginkan ruangan dari akumulasi panas udara dalam ruangan menggunakan AC mencapai $60 \%$ dari total energi [4]. Dimana $80 \%$ beban panas dalam rumah hunian dipengaruhi desain envelopenya (desain dinding, dan atap rumah), disamping sumber-sumber panas lainnya.

Di Indonesia terdapat berbagai macam atap diantaranya atap datar, atap pelana, atap perisai dan ada beberapa yang lainnya. Bedasarkan arah kemiringan, atap dibagi kedalam tiga macam yaitu atap datar dengan kemiringan $<10^{\circ}$, Landai dengan kemiringan antara $10^{\circ}$ sampai $30^{\circ}$ dan miring dengan kemiringan $>30^{\circ}$ [5]. Dimana disetiap kemiringan tersebut akan ada perbedaan termal yang didapatkan pada suhu ruangan. Dalam penelitian Rury mengenai upaya untuk menurunkan panas yang bersumber dari desain atap bangunan dan material atap, dapat diambil hasil bahwa bentuk atap miring atau disebut perisai $\left(>30^{\circ}\right)$ merupakan bentuk paling baik karena mampu menciptakan kondisi termal dalam ruangan yang lebih baik dibanding desain dengan kemiringan datar atau landai [5]

Disamping itu, karena Indonesia terletak di daerah rawan gempa maka desain atap harus dirancang dengan kekuatan yang memadai dan bobot material yang minimal. Semakin tinggi sudut kemiringan atap, semakin rendah perpindahan panas yang melewati loteng. Namun sebaliknya, semakin banyak pula material atap yang digunakan sehingga bobot atap akan semakin bertambah. Oleh karena ini perlu dilakukan optimasi pemilihan sudut kemiringan atap yang optimal dengan mempertimbangkan aspek kenyamanan termal dan bobot material.

Berdasarkan penjabaran di atas, diketahui bahwa sebuah bangunan tropis yang ideal harus mampu meminimalkan problem perolehan panas matahari. 


\section{METODE PENELITIAN}

Penelitian yang digunakan adalah metode analisis numerik dengan menggunakan software Google SketchUp, CONTAM dan TRNSYS. Penelitian ini dilaksanakan untuk melakukan optimasi kemiringan atap dan berat struktur atap terhadap kenyamanan temperatur ruangan dan perhitungan bangunan tahan gempa. Penelitian ini menguji rumah dengan panjang 8 meter, lebar 6 meter dan tinggi 3 meter. Rumah ini di variasikan dengan beberapa sudut kemiringan atap yang berbeda yaitu $15^{\circ}, 20^{\circ}, 25^{\circ}, 30^{\circ}, 35^{\circ}, 40^{\circ}$ dan $45^{\circ}$ menggunakan model atap pelana di desain dengan software SketchUp. Pada sudut atap yang di teliti, digunakan perbedaan sudut dengan selisih $5^{\circ}$ agar dapat dilihat perbandingan yang jelas. Pada gambar yang dibuat di SketchUp, dihitung laju aliran udara bangunan dan tekanan relatif antara zona bangunan menggunakan CONTAM. Selanjutnya data yang dibuat akan disimulasikan menggunakan software TRNSYS. Sebelum disimulasikan edit beberapa poin yang ada dalam software TRNSYS, seperti infiltrasi, scenario penghuni, jumlah penghuni dan beberapa lainnya. Setelah itu simulasikan menggunakan TRNSYS tersebut dengan rentang waktu simulasi selama 1 tahun.

\section{HASIL DAN PEMBAHASAN}

Dari simulasi yang dilakukan diperoleh temperature pada 2 zona yaitu pada rumah dan loteng. Pada zona rumah akan didapatkan 2 hasil temperatur yaitu temperatur operatif dan temperatur udara. Pada zona rumah,temperature yang dianalisis adalah temperature operatif. Karena temperatur operatif merupakan suhu akhir yang telah dipengaruhi oleh beberapa benda yang mengeluarkan energy panas seperti alat elektronik, panas tubuh, panas dinding dan suhu udara didalam ruangan.

Pada zona loteng, juga menghasilkan 2 hasil data yaitu temperatur operatif dan temperatur udara. Pada zona loteng, temperature yang dianalisis adalah temperatur udara karena pada zona loteng tidak terdapat benda-benda yang berpengaruh terhadap suhu di dalamnya. Berikut hasil dari kedua zona tersebut.

Temperatur dan Kondisi Kenyamanan Termal pada Rumah Perbandingan temperatur operatif pada tanggal 1-3 Januari.

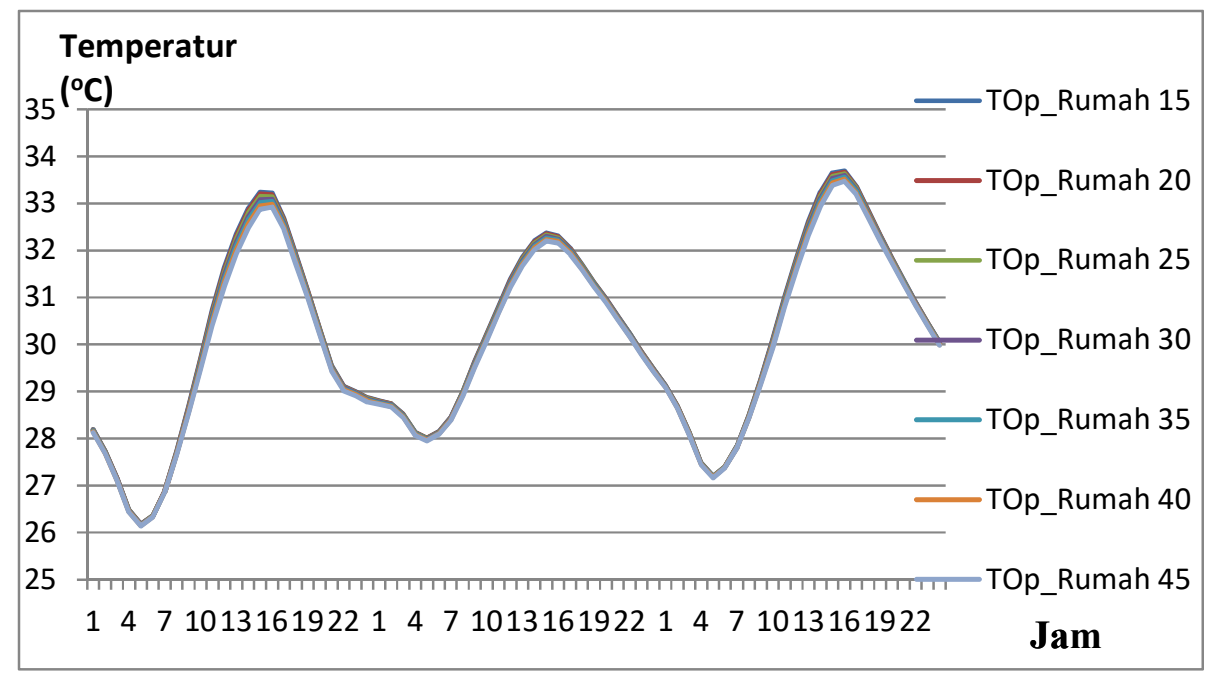

Gambar 1. Grafik Temperatur operatif rumah pada tanggal 1-3 januari.

Pada grafik gambar 1 dapat dilihat perbandingan antara temperature operatif beberapa sudut atap yang diteliti. Mulai pada awal tahun yaitu pada 1 januari pada jam 01:00 
temperatur operatif di rumah dengan sudut $15^{\circ}$ yaitu $28,18^{\circ} \mathrm{C}$, sudut $20^{\circ}$ berada pada 28,17 ${ }^{\circ} \mathrm{C}$ dan temperatur selalu turun jika sudut atap semakin tinggi. Dapat dilihat pada sudut atap $45^{\circ}$ temperaturnya yaitu $28,12{ }^{\circ} \mathrm{C}$ saja. Ini disebabkan karena pada sudut $45^{\circ}$ memiliki ruang yang lebih besar dibandingkan sudut lainnya, ruang yang besar inilah membuat penyerapan panas menjadi lebih maksimal.

Pada tangal 1 januari ini, temperatur terendah berada pada jam 05:00 dan itu terjadi pada semua sudut. Terjadi karena pada malam hari rumah tidak mendapat radiasi dari matahari dan pada jam 5 tersebut bumi paling banyak melepaskan energy panas.

Pada siang hari, yaitu jam 12:00 temperatur pada sudut $15^{\circ}$ berada pada titik $31,63{ }^{\circ} \mathrm{C}$ dan temperaturnya selalu turun jika sudut atap semakin besar seperti pada sudut $45^{\circ}$ temperaturnya berada pada titik $31,24^{\circ} \mathrm{C}$. Sudut $15^{\circ}$ memiliki temperatur yang paling tinggi dibandingkan sudut yang lainnya, ini terjadi karena pada sudut $15^{\circ}$ memiliki ruang loteng yang kecil dibandingkan sudut lainnya.

Dari grafik gambar 1 yang didapatkan di rumah pada siang hari, memperlihatkan bahwa antara temperatur sudut $15^{\circ}, 20^{\circ}, 25^{\circ}$ sampai $45^{\circ}$ memiliki tendensi (pola) yang sama dimana pada saat sudut atap semakin tinggi maka temperatur yang didapatkan akan semakin turun.

\section{Perbandingan temperatur operatif pada tanggal 1-3 juni}

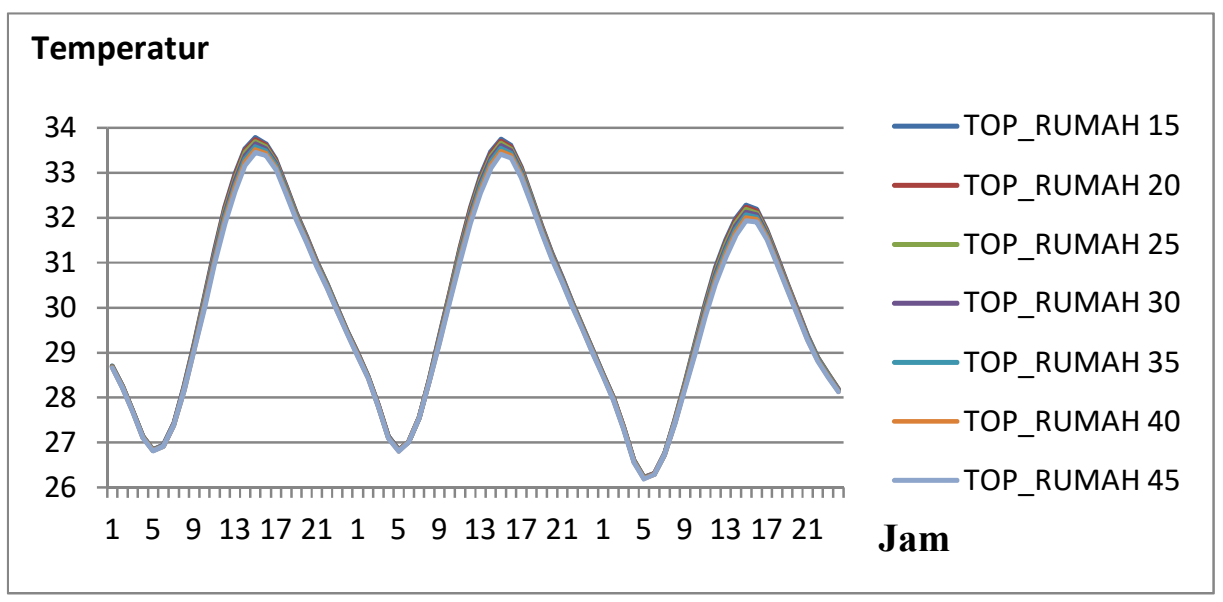

Gambar 2. Grafik Temperatur operatif rumah pada tanggal 1-3 juni.

Pada tanggal 1-3 Juni tidak terjadi perbedaan pola antara sudut $15^{\circ}, 20^{\circ}, 25^{\circ}$ sampai $45^{\circ}$. Dengan pola semakin tinggi sudut maka semakin rendah temperatur didadamnya. Tetapi pada jam 01:00 juni temperatur pada sudut $15^{\circ}$ mencapai $28,69{ }^{\circ} \mathrm{C}$ yang berarti temperatur pada bulan juni meningkat dibandingkan temperatur sudut $15^{\circ}$ pada jam 01:00 tanggal 1 januari yang hanya $28,18{ }^{\circ} \mathrm{C}$ dengan selisih $0,51{ }^{\circ} \mathrm{C}$. Pada bulan juni temperatur tertinggi mencapai $33,78{ }^{\circ} \mathrm{C}$ sedangkan pada bulan januari hanya $33,68{ }^{\circ} \mathrm{C}$. Temperatur yang tinggi di bulan juni disebabkan karena pada bulan juni terjadi musim kemarau.

Nilai degree hour thermal discomfort (temperatur diatas $27^{\circ} \mathrm{c}$ ) rumah untuk beberapa kasus kemiringan atap.

Pada analisis ini, dihitung berapa jumlah temperatur yang berada pada titik diatas $27{ }^{\circ} \mathrm{C}$ selama setahun yang mana jika temperatur didapatkan berada di bawah $27{ }^{\circ} \mathrm{C}$ maka dianggap 0 (nol) karena dalam analisis ini cuma dihitung kelebihan temperatur nya saja. Pada saat menghitung temperatur diatas $27{ }^{\circ} \mathrm{C}$, didapatkan kelebihan temperatur pada sudut $15^{\circ}$ sebanyak 22982,28 ${ }^{\circ} \mathrm{C}$ per tahun. Ini merupakan Degree Hour Thermal Discomfort paling tinggi pada semua sudut lain. Disebabkan karena banyaknya kelebihan temperatur di atas 27 ${ }^{\circ} \mathrm{C}$, karena ukuran sudut sangat mempengaruhi temperatur di dalamnya. Semakin kecil sudut 
maka semakin kecil ruang di dalamnya sehingga membuat penyerapan panas kurang maksimal dibandingkan rumah dengan sudut atap yang lebih besar.

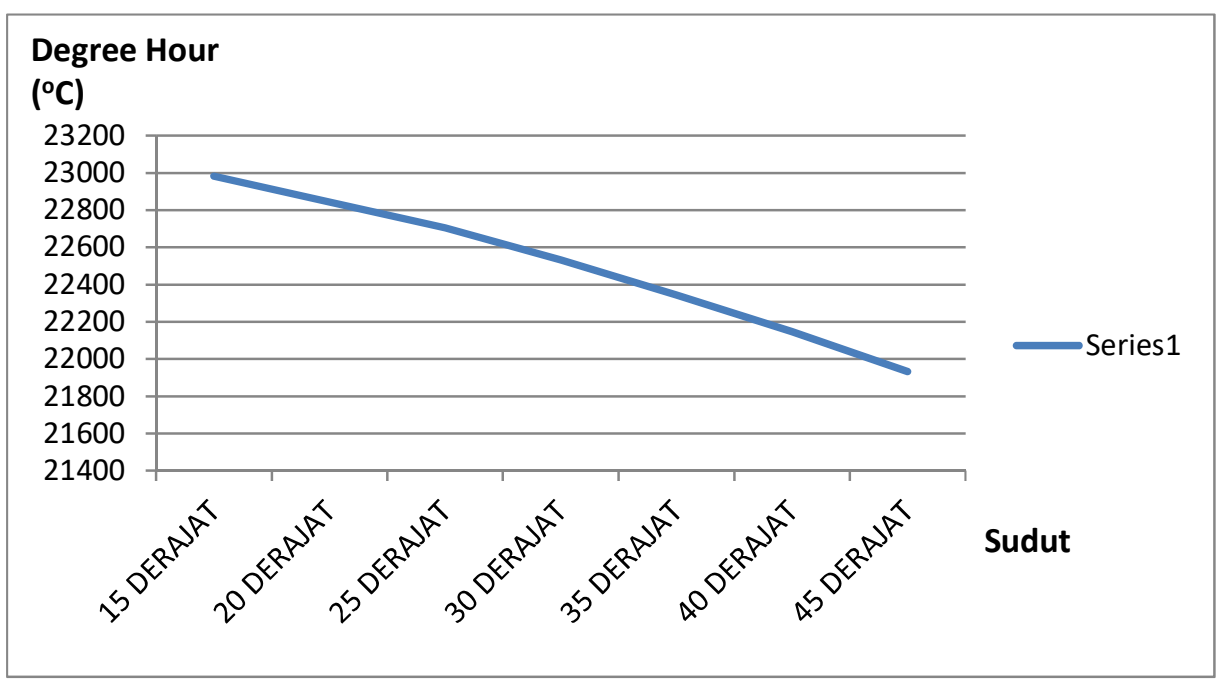

Gambar 3. Grafik Nilai Degree Hour Thermal Discomfort rumah

Sudut $20^{\circ}$ sebanyak $22844,11^{\circ} \mathrm{C}$ per tahun, sudut $25^{\circ}$ sebanyak $22703,7{ }^{\circ} \mathrm{C}$ per tahun dan semakin rendah temperaturnya apabila semakin tinggi sudutnya. Dapat disimpulkan bahwa semakin tinggi sudut atap maka semakin sedikit jumlah kelebihan temperatur. Ini berbanding lurus dengan semakin tinggi sudut atap maka semakin rendah temperatur di dalam rumah.

Nilai Degree Hour Thermal Discomfort terendah berada pada atap pelana dengan sudut $45^{\circ}$ yaitu $21931,78{ }^{\circ} \mathrm{C}$ per tahun. Ini berarti sudut atap pelana yang paling nyaman termalnya adalah atap pelana dengan sudut $45^{\circ}$.

\section{Perbandingan temperatur operatif rata rata pada rumah}

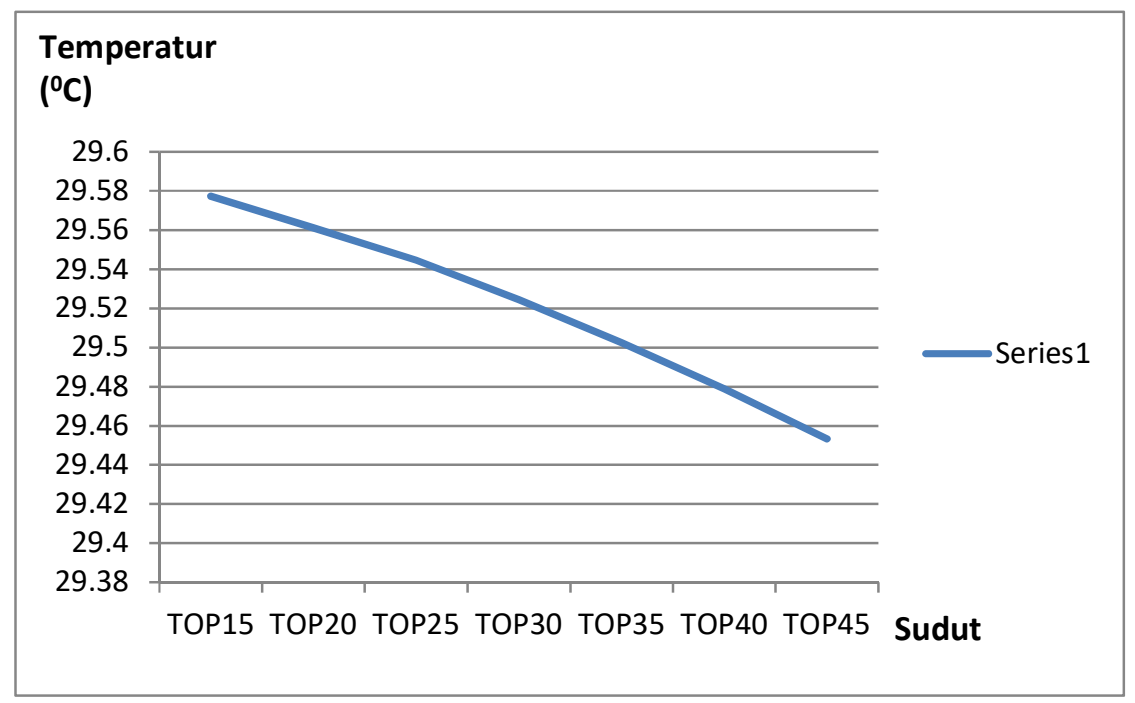

Gambar 4. Grafik Temperature operatif rata rata pada rumah

Temperatur operatif rata rata pada rumah dengan sudut $15^{\circ}$ adalah $29,57{ }^{\circ} \mathrm{C}$ sudut $20^{\circ}$ yaitu $29,56^{\circ} \mathrm{C}$ dan selalu turun jika sudut atap bertambah tinggi. Namun temperatur ini lebih 
tinggi dibandingkan pada malam hari, ini di karenakan pada siang hari rumah mendapatkan radiasi dari matahari. Pada rumah, temperatur operatifnya berbeda beda, sesuai dengan sudut atap yang digunakan pada rumah tersebut, semakin besar sudut yang digunakan pada atap maka semakin kecil pula temperatur di dalam rumah karena pada sudut atap yang besar memiliki ruang yang besar pula sehingga penyerapan panas dari matahari dapat dimaksimalkan pada loteng dan juga membuat udara panas tidak cepat diteruskan dalam zona rumah. Dapat disimpulkan bahwa semakin tinggi sudut atap maka semakin rendah temperatur di dalam zona rumah.

Temperatur operatif pada rumah ini dipengaruhi oleh banyak hal yaitu, temperatur tubuh penghuni, temperatur TV, radiasi matahari dan berbagai macam penyebab lainnya. Karena temperatur operatif adalah efek temperatur udara dan radiasi panas antara manusia dan permukaan di lingkungan. Dengan kata lain: temperatur operatif adalah rata-rata temperatur udara dan temperatur permukaan di sekitarnya

Perbandingan temperatur operatif rata rata rumah khusus siang hari pada sudut kemiringan atap yang berbeda.

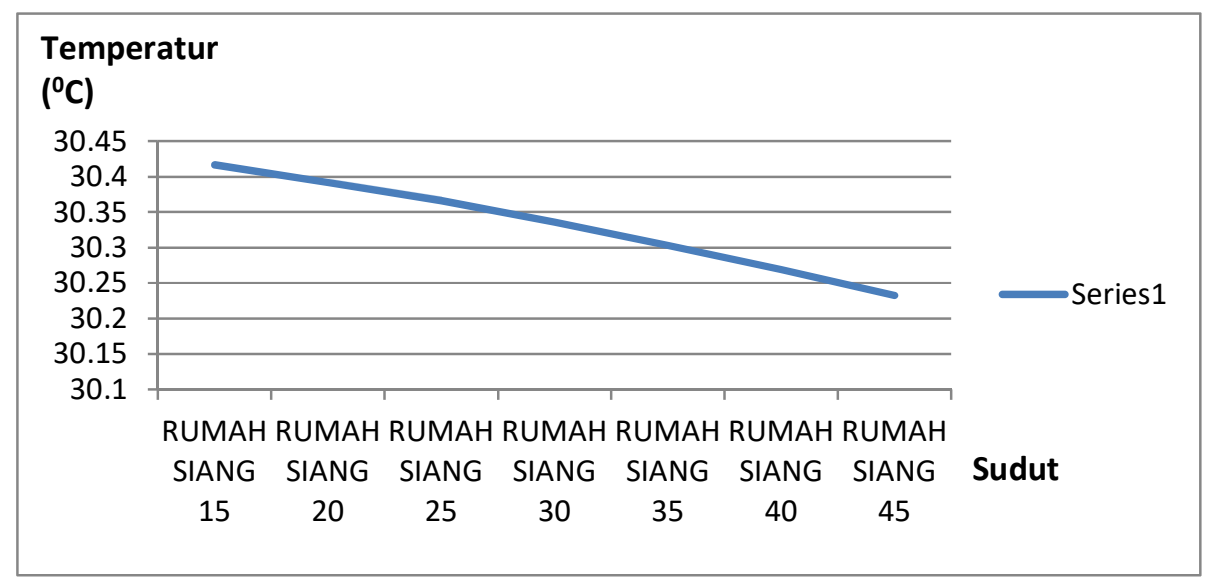

Gambar 5. Grafik Temperature operatif rata rata pada rumah khusus siang hari

Pada siang hari terdapat radiasi matahari yang langsung memancar ke atap sehingga pada atap terjadi pemanasan yang mengakibatkan panas masuk ke dalam zona rumah. Sehingga pada siang hari temperatur yang dirasakan akan menjadi lebih panas dibandingkan malam hari. Pada grafik ini dijelaskan bahwa semakin tinggi sudut atap maka semakin rendah pula temperatur di dalam rumah. Bisa dilihat pada grafik pada sudut $15^{\circ}$ temperatur rata rata berada pada $30,41^{\circ} \mathrm{C}$ dan semakin turun jika sudut atapnya semakin tinggi dapat dilihat pada sudut $45^{\circ}$ yang temperatur rata ratanya hanya $30,23{ }^{\circ} \mathrm{C}$. temperatur operatif yang tinggi pada siang hari juga disebabkan oleh manusia itu sendiri, karena pada siang hari manusia banyak beraktifitas maka akan semakin besar juga energy panas yang manusia keluarkan sehingga energy tersebut diserap oleh rumah Lalu energy tersebut dilepaskan lagi sehingga manusia dapat merasakan energy panas tersebut.

Jumlah jam dengan temperatur di atas $27^{\circ} \mathrm{C}$

Dalam kenyamanan termal, penulis mengambil temperatur $27{ }^{\circ} \mathrm{C}$ sebagai acuan untuk perbandingan nyaman atau tidaknya termal pada suatu ruangan. Karena manusia akan terasa nyaman jika temperatur ruangan berada pada $27^{\circ} \mathrm{C}$ ke bawah. Sehingga pada setiap sudut yang di analisis akan di dapatkan pesentase jam yang temperaturnya lebih dari $27^{\circ} \mathrm{C}$. Dapat dilihat pada tabel, persentase tertinggi berada pada sudut $15^{\circ}$ dikarenakan pada sudut $15^{\circ}$ ini didapatkan jam terbanyak yang berada pada temperatur di atas $27^{\circ} \mathrm{C}$ sedang kan persentase terendah berada pada sudut $45^{\circ}$ di karenakan semakin tinggi sudut atap maka semakin 
dingin ruangan tersebut sehingga juga berdampak pada persentase jam dengan temperatur di atas $27^{\circ} \mathrm{C}$. perhitungan persentase ini dengan cara menghitung jumlah jam di atas temperatur $27{ }^{\circ} \mathrm{C}$ lalu di bagi dengan jumlah jam selama setahun yaitu 8760 jam. Sehingga akan didapatkan persentase tersebut.

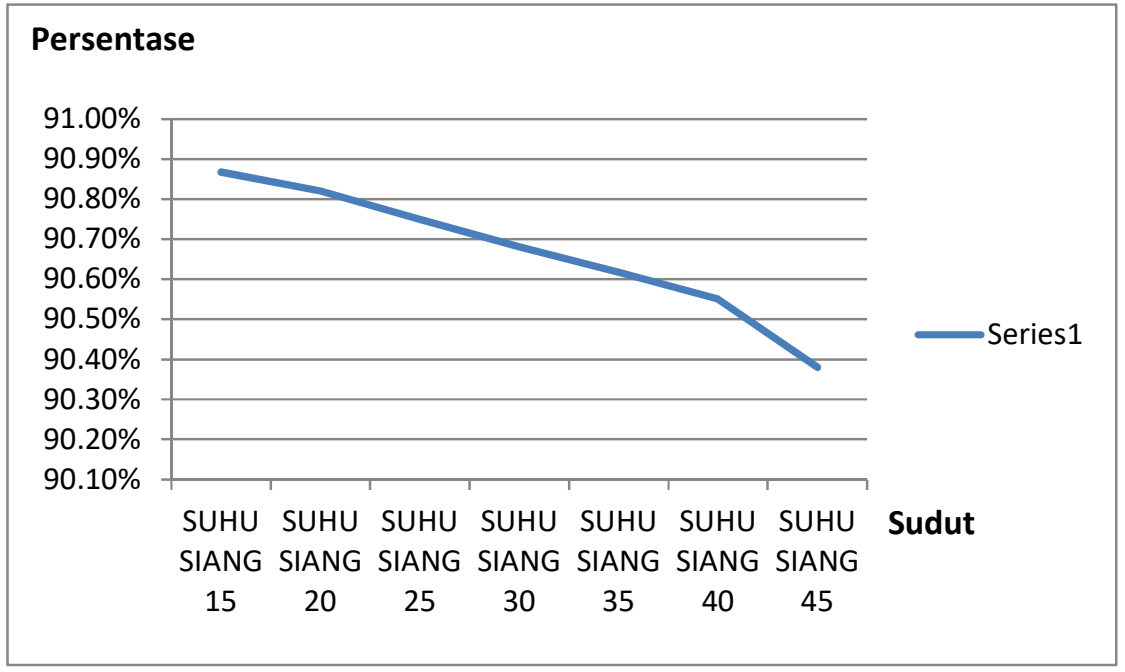

Gambar 6. Grafik Jumlah jam dengan temperature di atas $27^{\circ} \mathrm{C}$.

\section{Temperatur pada Loteng} Perbandingan temperature udara dalam zona loteng pada tanggal 1-3 januari.

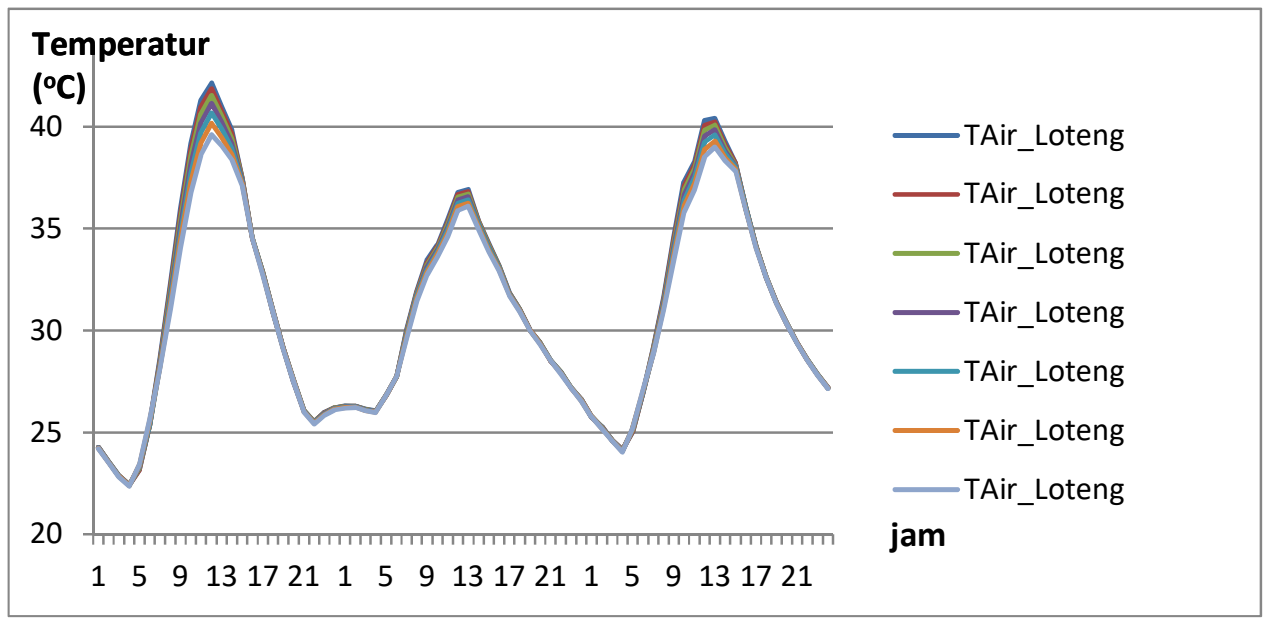

Gambar 7. Grafik Temperature udara dalam zona loteng pada tanggal 1-3 januari

Pada loteng, sangat jelas perbandingan temperatur udara pada siang hari jam 12:00 di tiap sudut. Pada sudut $15^{\circ} \mathrm{C}$ jam 12:00 tanggal 1 januari temperatur udara berada pada titik $42,14{ }^{\circ} \mathrm{C}$. Sudut $20^{\circ}$ yaitu $41,86^{\circ} \mathrm{C}$ selalu turun jika sudut atapnya semakin tinggi. Pada atap dengan sudut $45^{\circ}$ menjadi $39,6^{\circ} \mathrm{C}$. ini juga berbanding lurus dengan temperature operatif pada rumah dimana semakin tinggi sudut atap maka semakin kecil temperatur di dalamnya. Disebabkan oleh sudut yang lebih kecil sehingga juga memiliki ruang yang kecil dibandingkan sudut yang lebih besar, pada ruang yang kecil penyerapan panas udara akan kurang maksimal dibandingkan pada ruang yang lebih besar. Temperatur udara tertinggi berada pada tanggal 1 januari jam 12:00 di sudut $15^{\circ}$. ini karena pada jam 12:00 radiasi matahari yang diterima atap 
lebih banyak dibandingkan pada jam lain dan juga disebabkan oleh ruang yang kecil pada atap bersudut $1^{\circ}$. Sedangkan temperatur terendah berada pada jam 05:00 di semua sudut. Karena pada malam hari tidak terjadi radiasi oleh matahari sehingga tidak mengakibatkan perubahan temperatur yang signifikan.

Perbandingan temperature udara dalam zona loteng pada tanggal 1-3 juni

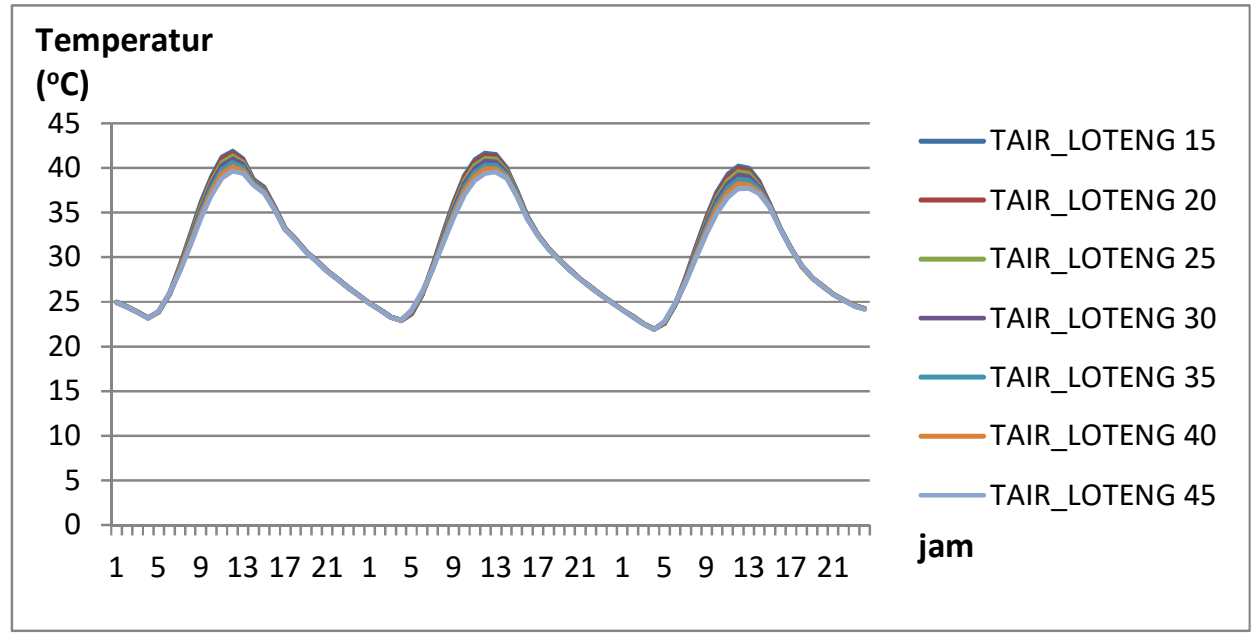

Gambar 8. Grafik temperature udara dalam zona loteng pada tanggal 1-3 juni.

Setelah di simulasikan, pada tanggal 1-3 juni, didapatkan temperatur tertinggi yang berada pada jam 12:00 tanggal 1 juni. Temperaturnya adalah $41,87{ }^{\circ} \mathrm{C}$ dengan sudut kemiringan atap $15^{\circ}$. disebabkan oleh radiasi matahari yang terpancar penuh ke arah atap sehingga atap mendapatkan banyak energy panas sedangkan pada atap $15^{\circ}$ ini ruang yang berada didalamnya kecil sehingga perolehan panas tersebut tidak dapat di sirkulasikan secara maksimal. Temperatur terendah yang didapatkan pada tanggal $1-3$ juni adalah $21,87{ }^{\circ} \mathrm{C}$ pada jam 04:00 tanggal 3 dengan kemiringan atap $45^{\circ}$. pada tanggal 1-3 juni ini akan lebih panas dibandingkan bulan januari karena pada bulan juni terjadi musim kemarau.

Temperature udara rata rata pada loteng

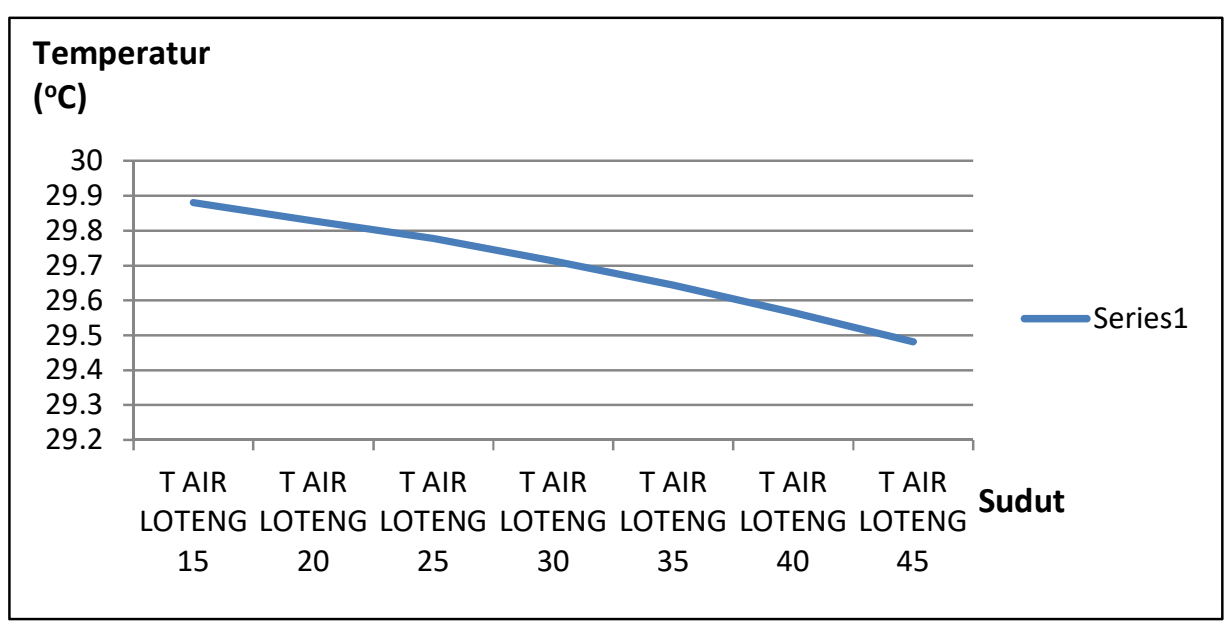

Gambar 9. Grafik Temperatur rata rata pada loteng

Temperatur rata rata pada loteng dengan sudut $15^{\circ}$ adalah $29,88{ }^{\circ} \mathrm{C}$ sudut $20^{\circ}$ yaitu 29,82 ${ }^{\circ} \mathrm{C}$ sudut $25^{\circ}$ yaitu $29,77^{\circ} \mathrm{C}$ dan selalu turun jika sudut atap bertambah tinggi. Ini di karenakan 
pada siang hari loteng mendapatkan radiasi langsung dari matahari dan semakin besar sudut atap maka semakin banyak ruang untuk udara. Temperatur udara pada loteng memang tidak terlalu besar perbedaannya dari temperatur operatif rata rata pada rumah karena temperatur pada loteng ini tidak terpengaruh oleh benda lain seperti TV, panas tubuh manusia, lampu, dan lain sebagainya.

Temperature udara rata rata siang hari pada loteng

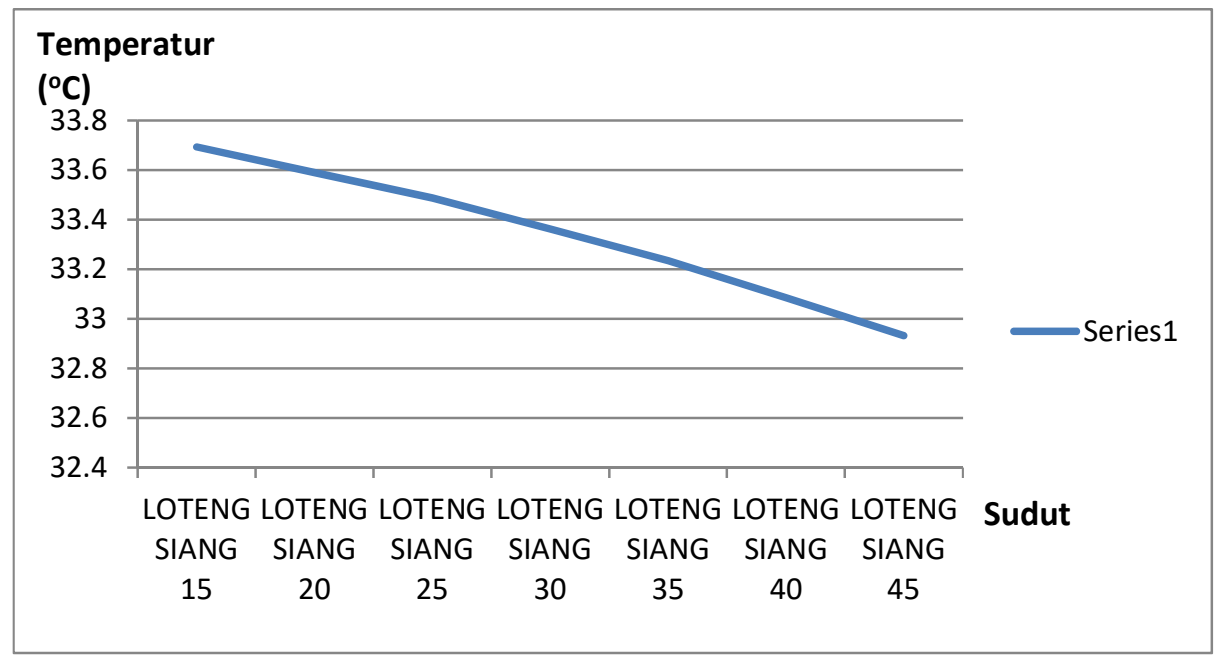

Gambar 10. Grafik Temperatur rata rata siang hari pada loteng

Pada siang hari memang loteng merupakan bagian pertama yang langsung berhadapan dengan radiasi matahari, akibatnya temperatur rata rata pada loteng ini akan lebih tinggi dibandingkan temperatur pada bagian rumah lainnya. Apalagi loteng yang sudutnya rendah akan membuat ruang pada loteng itu sendiri lebih kecil sehingga temperatur menjadi sangat panas karena udara tidak dapat terserap secara maksimal. Dapat di lihat pada loteng temperatur udara rata rata pada semua sudut berada di atas zona lainnya yang menandakan loteng lebih panas di bandingkan zona lain . Lihat saja pada loteng dengan sudut 150, temperatur udara nya bahkan mencapai $33,69{ }^{\circ} \mathrm{C}$ dan pada rumah temperatur operatifnya pun hanya $30,41^{\circ} \mathrm{C}$. Pada kasus ini bisa disimpulkan jika ingin memiliki temperatur rumah yang relatif rendah maka desain lah rumah dengan kemiringan atap yang tinggi. Karena ruang loteng yang tercipta akan semakin besar. Sehingga loteng tersebut lebih maksimal dalam menyerap panas.

\section{SIMPULAN DAN SARAN}

\section{Simpulan}

Kemampuan atap dalam menciptakan kenyamanan termal yang baik adalah atap dengan kemiringan $45^{\circ}$ karena pada kemiringan ini degree hour thermal discomfortnya tidak terlalu tinggi.

Saran

Untuk penelitian selanjutnya sebaiknya simulasikan dengan data yang lebih rinci seperti menambahkan benda-benda yang menghasilkan energy panas contohnya kulkas, kompor dan lain sebagainya.

Sebelum melakukan simulasi pada TRNSYS sebaiknya rancang bangunan sesuai standar agar hasil simulasi menjadi akurat.

Dalam melakukan simulasi sebaiknya lakukan dalam rentang waktu 2 tahun dan ambil data dari tahun kedua karena pada tahun pertama data yang di dapatkan kurang akurat. 
Hasil dari penelitian ini masih belum memenuhi criteria nyaman, untuk itu disarankan untuk penelitian berikutnya agar menggunakan jenis atap yang lainnya agar dapat memenuhi criteria nyaman.

Untuk masyarakat yang ingin mengetahui kemiringan atap yang efektif untuk meminimalisir energy panas dan untuk pertimbangan rumah tahan gempa, penelitian ini dapat digunakan sebagai pertimbangan dalam memilih kemiringan atap yang digunakan.

\section{DAFTAR RUJUKAN}

[1] Lippsmeier, G. 1994. "BangunanTropis. EdisiKedua”. Terjemahan. Jakarta: Erlangga.

[2] Rilatupa, J. 2008 ."Aspek Kenyamanan Termal pada Pengkondisian Ruang Dalam”.EMAS Jurnal Sain dan Teknologi, 18(3), pp.pp-191.

[3] Prianto, E. 2012. "Strategi Disain Fasad Rumah Tinggal Hemat Energi."Jurnal Pembangunan Kota Semarang RIPTEK.1(6).Hlm. 55-65.

[4] Satwiko, Prasato. 2004. Fisika Bangunan 2. Edisi Pertama. Yogyakarta: Andi.

[5] Rury, N. (2016). "Pengaruh Material Dan Bentuk Atap Rumah Tinggal terhadap Suhu di Dalam Ruang". Jurnal Penelitian dan Karya Ilmiah Arsitektur Usakti, 15(1). 